\title{
Preface
}

\section{Giuliano Amato}

Gustavo Ghidini has an excellent grasp of both the principles and the many specific provisions underlying intellectual property law in Italy and Europe. Nevertheless, he is neither a dogmatist nor an exegete immersed within the horizon of the texts he reads. He has a powerful vision of the politics of law, regularly setting it out in his premises and grounding it in his interpretation of current principles, which he justifies. He then projects it in his examination of concepts and individual regulations, which sometimes corroborate it but in other cases refer back to it, and on yet other occasions contradict it - at which point Ghidini observes that the original idea was wrong. This is why Ghidini's books are never dull. Just the opposite: they are always warm, argumentative and intent on proving a hypothesis. As a result, his works are far more enjoyable than conventional law books and the merit is his alone, because he goes beyond the most rigorous standards of scientific soundness and plainly legal analysis.

Experts on industrial property and antitrust law are very familiar with his vision of the politics of law. Nonetheless, Ghidini, who also appreciates - and practises - economic analysis, has never accepted the conclusions reached by the school that, more than any other, established this field: the Chicago School. Thus, he has never replaced efficiency with competition as the ultimate aim on which to base regulations and decisions concerning the market. Consequently, he has never ceased to promote the openness and well-being of the consumer, achieved by not reducing output and by the variety of possible choices, nor has he ever been ashamed of the legal opinion - once American but now purely European - according to which, in some cases, the weakest competitors must be protected in order to protect competition.

In the context of such a vision, the monopoly rights of intellectual property law - patents, copyrights and trademarks - are embraced if and as long as they are consistent with 'the guiding principle of free competition', whereas the laws governing them must preferably be interpreted from a pro-competitive standpoint. As Ghidini rightly points out, however, this does not go against their nature by any means. Indeed, their juxtaposition with competition couldn't be simpler, given the monopoly element that characterises them, but their ultimate purpose is to make the market more competitive. 
Ghidini is quite harsh towards industrial countries as well as TRIPs (which have denied emerging countries what industrial countries once granted to themselves). At the same time, however, he goes to great pains to distance himself from the generalised and often ideological 'no global' protest against these same targets, accusing this protest of completely ignoring the reasons for protecting investments earmarked for research. Furthermore, and precisely because he, in turn, does not think along ideological lines, he is also very careful to avoid generalising the claim that monopoly rights have counterproductive effects, since, in reality, these have emerged only in specific sectors. And he cites network industries, starting with communications, biotechnologies, and automotive and household-appliance components, and culminating with the 'rapidly expanding frontier' of areas (chiefly communications for the time being) in which consumers can interact with manufacturers and redevelop, integrate and transform the product or service they are receiving. But when this happens - he wonders - what then is the meaning of traditional absolute protections?

No one, not even those who usually disagree with Ghidini, can deny the meaning and implications of such a question. This kind of necessary acknowledgement is the best reward for his vision and for the steadfastness - never aprioristic nor unwarranted - with which he applies it. It is thanks to this vision that he grasps change and, more rapidly and readily than others, notes its effects on law and previous legal opinions, to which one cannot remain indiscriminately faithful when their impact given a changed reality generates effects that are the opposite of the ones that warranted them in the first place.

A great legal scholar, Carlo Esposito, wrote that not only regulations but even principles themselves do not express absolute truths, but rather incorporate contingently persuasive practical reasons. Consequently, rules must remain in place as long as the principles that they express continue to be valid, but they must be changed when it turns out that they are no longer shared and perhaps other rules are de facto taking their place. Perhaps Esposito, who loved to go to extremes in his reasoning, overshot the mark by denying the absolute value of any principle and submitting to actuality. Of course, if regulation of the wheel had been based on the wheel being square and then someone finally invented a round wheel, such regulation could hardly remain the same. Esposito was unquestionably right about this, and it is this very subject that Ghidini discusses in his book. Those who fail to heed him are doing so entirely at their own risk. 